QUARTERLY TECHNICAL PROGRESS REPORT

AND KEY PERSONNEL STAFFING REPORT

NUMBER 11

PRODUCTION AND SCREENING OF CARBON PRODUCTS PRECURSORS FROM COAL

CARBON PRODUCTS CONSORTIUM

CONTRACT NO. DE-AC22-95PC94063

\title{
REPORTING PERIOD:
}

July 1, 1997 to September 30, 1997

Submitted to:

AAD Document Control Center

U.S. Department of Energy

Pittsburgh Energy Technology Center

PO Box 10940, MS 921-143

Pittsburgh, PA 15236-0940

\section{Submitted by:}

West Virginia University Research Corporation on behalf of West Virginia University

886 Chestnut Ridge Road

Morgantown, WV 26506

October, 1997

Table of Contents 


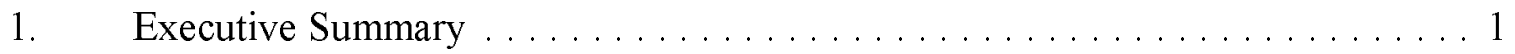

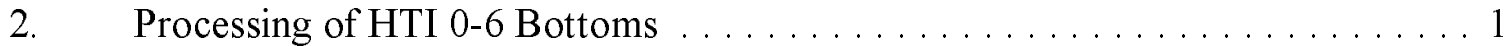

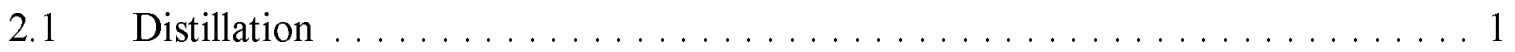

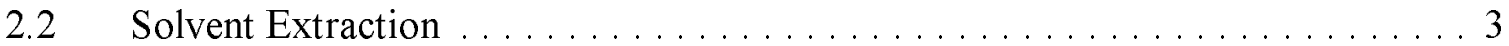

$2.3 \quad$ Other HTI Coal Products $\ldots \ldots \ldots \ldots \ldots \ldots \ldots \ldots \ldots \ldots \ldots \ldots$ 


\section{List of Tables}

Table 1. Material balance for pilot-scale distillation of HTI-0-6 bottoms, $\ldots \ldots 2$

Table 2. Material balance for pilot-scale distillation of HTI $0-6$ bottoms, . . . . 2

Table 3. Designation of HTI Coal-derived products. $\ldots \ldots \ldots \ldots \ldots \ldots \ldots$

Table 4. Characterization of as-received PFL $\ldots \ldots \ldots \ldots \ldots \ldots$

Table 5. Characteristics of as-received PFS material $\ldots \ldots \ldots \ldots \ldots \ldots$

Table 6. Characteristics of NMP-Soluble portion of PFS-227-102-14A . . . . 6 


\section{List of Figures}

Figure 1. Photomicrograph of green coke from PFL $\ldots \ldots \ldots \ldots \ldots \ldots$

Figure 2. Photomicrograph of PFS-227-102-14A green coke .......... 5

Figure 3. Photomicrograph of NMP-Soluble $\ldots \ldots \ldots \ldots \ldots \ldots \ldots \ldots$ 


\section{Executive Summary}

The U.S. DOE Office of Fossil Energy is interested in the coproduction of coal liquids and carbon precursors. The DOE project manager has arranged for Hydrocarbon Technologies, Inc. (HTI) to provide the WVU researcher team with samples of stage-one, mildly hydrogenated coal liquids. Distillation and extraction process are being developed which produce a potential carbon anode precursor from the HTI material. The results obtained thus far seem to indicate that a coal-derived, pitch-like material can be developed from the HTI liquefaction product after distillation to remove liquefaction solvent and NMP extraction to eliminate mineral matter. The physical properties of the liquid are not unreasonable when compared to other types of available pitches. The molecular arrangement and the optical structures present in the green coke of the de-ashed coal liquid may be suitable for the production of anodes for aluminum manufacture, but more testing needs to be conducted to confirm this.

\section{Processing of HTI 0-6 Bottoms}

As reported previously, initial characterization of the Hydrocarbon Technology, Inc. (HTI) coal liquid (designated 0-6 Bottoms, Run 227-102) was promising for its use in making calcine coke for anode production after removal of the distillate fraction and deashing by NMP extraction. However, testing of a larger quantity of material will be required to confirm the suitability of the HTI liquid for coal-derived carbon products.

To accomplish this goal, Koppers has graciously allowed WVU to use its pilotscale vacuum distillation unit and personnel located at the technical center in Harmarville, PA. Approximately $32 \mathrm{~kg}$ total of vacuum distilled coal liquid have been prepared in two batches at the Harmarville facility.

\subsection{Distillation}

About one-half of the HTI coal liquid was distilled in the first batch with no unusual difficulty or problem. The pot area of the distillation unit was gradually brought to $350 \circ \mathrm{C}$ while under vacuum and samples withdrawn at regular time intervals for the measurement of softening point temperature. After a softening point temperature of about $125 \circ \mathrm{C}$ was reached, power to the heaters on the distillation unit was removed. The contents remaining in the distillation unit were allowed to cool slightly before transferal of the pitch to a receiving container.

About $30 \mathrm{wt} \%$ of distillate was removed from the initial amount of HTI coal liquid charged to the distillation unit. This quantity of distillate is somewhat lower than that produced earlier in the WVU laboratory, possibly because of the size and scale of the Koppers distillation unit. Table 1 below gives the results of mass considerations for batch number 1 . 
Table 1. Material balance for pilot-scale distillation of HTI O-6 bottoms, batch number 1

\begin{tabular}{|l|c|}
\hline Amount of HTI Coal Liquid Charged, g & 23,035 \\
\hline Total Distillate, g & 6,228 \\
\hline & \\
Total Pitch, g & 16,222 \\
\hline Softening Point of Pitch, $\circ \mathrm{C}$ & 124.9 \\
\hline & \\
Yield of Pitch, wt $\%$ & 70 \\
\hline
\end{tabular}

The second batch was obtained under similar conditions by raising the distillation pot temperature gradually to $350 \circ \mathrm{C}$ while the unit was under vacuum. Samples of pitch were again withdrawn from the pot area at regular intervals for the determination of softening point temperature. When the softening point temperature of the pitch had reached about $130 \circ \mathrm{C}$, distillation was stopped and the pitch allowed to cool somewhat before transferal to a metal container. Mass balance data following the distillation of the second batch are provided in Table 2 .

Table 2. Material balance for pilot-scale distillation of HTI O-6 bottoms, batch number 2

\begin{tabular}{|l|c|}
\hline & 23,131 \\
\hline Amount of HTI Coal Liquid Charged, g & 6,472 \\
\hline Total Distillate, g & 16,353 \\
\hline Total Pitch, g & 130.0 \\
\hline Softening Point of Pitch, ${ }^{-C}$ & 70.7 \\
\hline
\end{tabular}

The distilled coal liquid was subsequently shipped to the chemical engineering laboratory at West Virginia University for additional processing. WVU continues to make good progress in deashing and purifying the distilled coal liquid. Between 3 to $4 \mathrm{~kg}$ per week are being treated by solvent extraction with N-methyl pyrrolidone (NMP). At the time of this reporting period, nearly $15 \mathrm{~kg}$ of extracted and deashed pitch are available for 
evaluation or coking. We anticipate completion of the NMP-extraction process sometime in October.

\subsection{Solvent Extraction}

The steps involved in the removal of ash and other solids are carried out by placing about $800 \mathrm{~g}$ of the distilled O-6 bottoms in a 10-L flask along with $6 \mathrm{~L}$ of NMP. The solution is stirred for 1 hour at elevated temperature while at atmospheric pressure. The mixture is cooled and transferred to a centrifuge. Solids are removed under a force of $2000 \mathrm{G}$ and the supernatant liquid then decanted into a large rotary evaporator to strip off NMP for recycle. The deashed pitch is finally vacuum dried at $170 \circ \mathrm{C}$ overnight under a slight purge of nitrogen before weighing and storage in a cold room. This batch procedure will be repeated several times until all of the distilled O-6 bottoms is processed.

\subsection{Other HTI Coal Products}

HTI has also provided several samples of pressure filter liquids (PFL) and pressure filter solids (PFS) for examination by WVU. Table 3 identifies what the samples are as labeled on their containers.

Table 3. Designation of HTI coal-derived products

\begin{tabular}{|c|c|}
\hline Material Type & Designation \\
\hline Pressure Filter Liquid & $227-100-10,11,14$ \\
\hline Pressure Filter Liquid & $227-102-13 \mathrm{~A}$ \\
\hline Pressure Filter Solid & $227-102-14 \mathrm{~A}$ \\
\hline Pressure Filter Solid & $227-102-14 \mathrm{~B}$ \\
\hline Pressure Filter Solid & $227-102-15 \mathrm{~B}$ \\
\hline
\end{tabular}

Samples PFL 227-100-10,11,14 and PFS 227-102-14A have undergone preliminary testing. The results for the former are presented in Table 4 and a photomicrograph of the green coke shown in Figure 1. 
Table 4. Characteristics of as-received PFL

\begin{tabular}{|c|c|}
\hline Designation & $227-100-10,11,14$ \\
\hline Softening Point, ${ }^{\circ} \mathrm{C}$ & Room Temperature \\
\hline Coke Yield, wt\% & 24.9 \\
\hline Ash Content, wt\% & 1.4 \\
\hline
\end{tabular}

This particular PFL material flows readily at room temperature. Currently, it is not known whether the low softening point temperature is inherent to the sample or because of the inclusion of liquefaction solvent. Efforts are being made to contact HTI for additional information on the processing conditions used and will be reported on later.

The coke yield is rather low, being only about $25 \mathrm{wt} \%$. The low yield is consistent with the low softening point temperature, indicating the light nature of the PFL. The ash content appears to be high for a filtered product. As is evident in Figure 1, the ash content seems to interfere with the development of anisotropy. It is suggested that the low coke yield, high ash content, and restricted molecular alignment would preclude this PFL product as a candidate for anode coke or binder pitch.

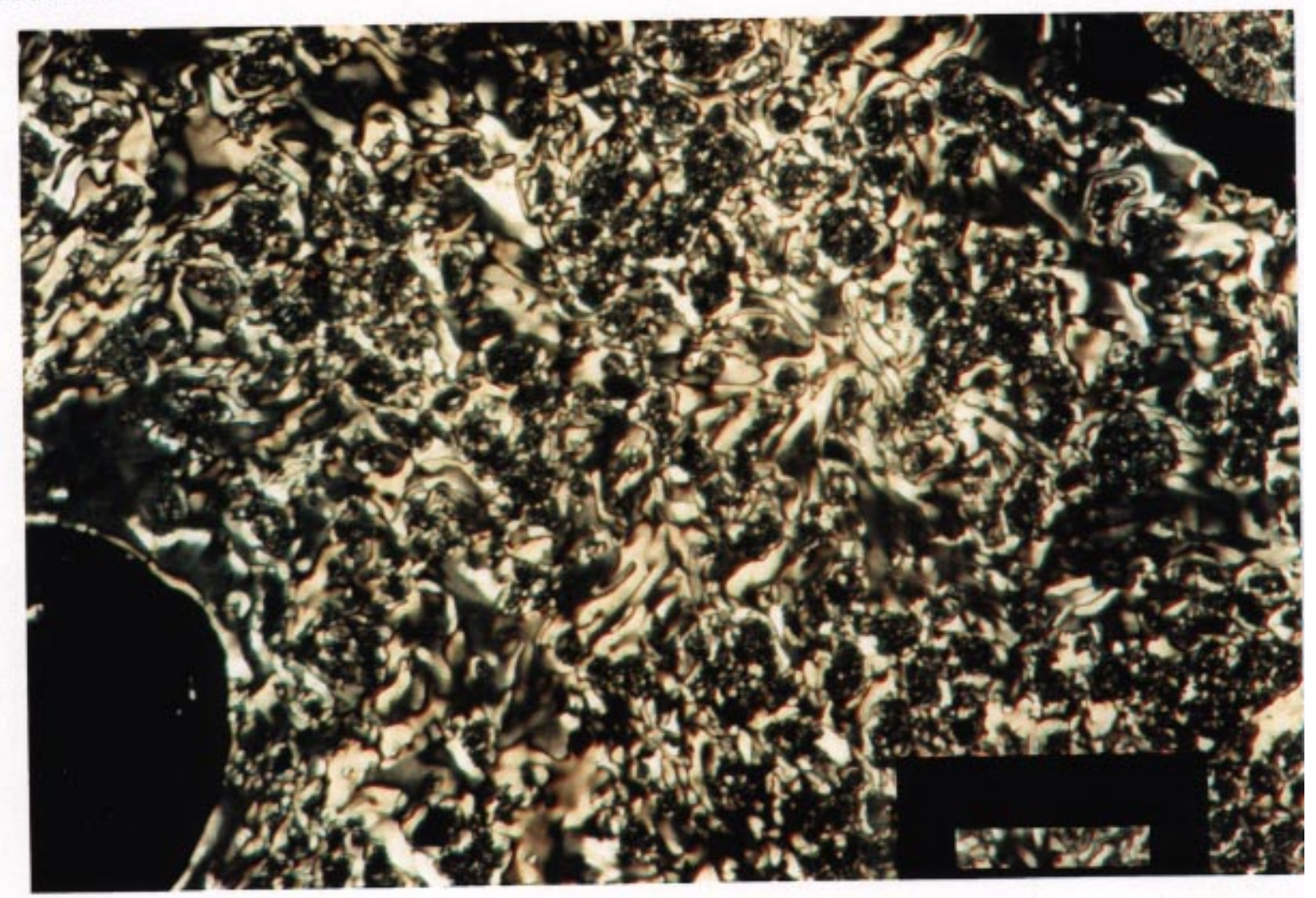

Figure 1. Photomicrograph of green coke from PFL 
The PFS sample is the filter cake formed after passage of liquefied coal through HTI's filtration unit. Some properties of the as-received PFS are presented in Table 5 and a photomicrograph of its green coke shown in Figure 2.

Table 5. Characteristics of as-received PFS material

\begin{tabular}{|l|c|}
\hline Identification & PFS-227-102-14A \\
\hline Quinoline Insolubles, wt\% & 62 \\
\hline Coke Yield, wt $\%$ & 71.4 \\
\hline & \\
Ash Content, wt $\%$ & 48.6 \\
\hline
\end{tabular}

Because the PFS is essentially a residue, its ash content and quinoline insolubility are very high. Moreover, examination of the green coke structure reveals that the PFS develops a coke that is highly isotropic.

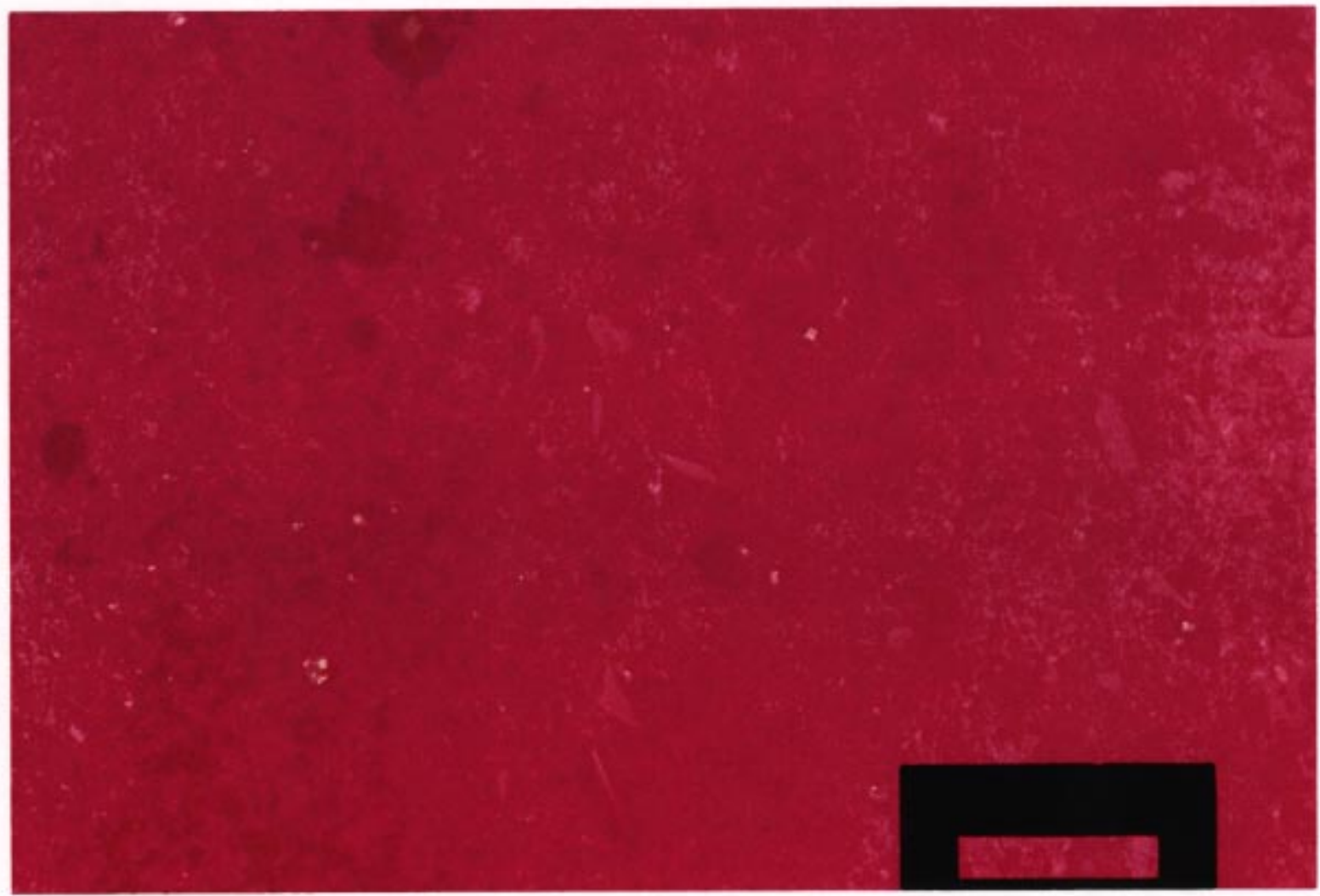

Figure 2. Photomicrograph of PFS-227-102-14A green coke 
A sample of the PFS was dissolved in NMP and the solids removed by centrifugation. The NMP-soluble portion was isolated and tested for physical properties, Table 6. A portion of the NMP-solubles was also converted into green coke and a photomicrograph presented in Figure 3.

Table 6. Characteristics of NMP-soluble portion of PFS-227-102-14A

\begin{tabular}{|l|c|}
\hline NMP Solubles, wt\% & 37 \\
\hline Softening Point, $\circ \mathrm{C}$ & 82.1 \\
\hline & \\
Density, $\mathrm{g} / \mathrm{cm}^{3}$ & 1.195 \\
\hline Coke Yield, wt\% & 37.5 \\
\hline & \\
Ash Content, wt\% & 0.7 \\
\hline
\end{tabular}

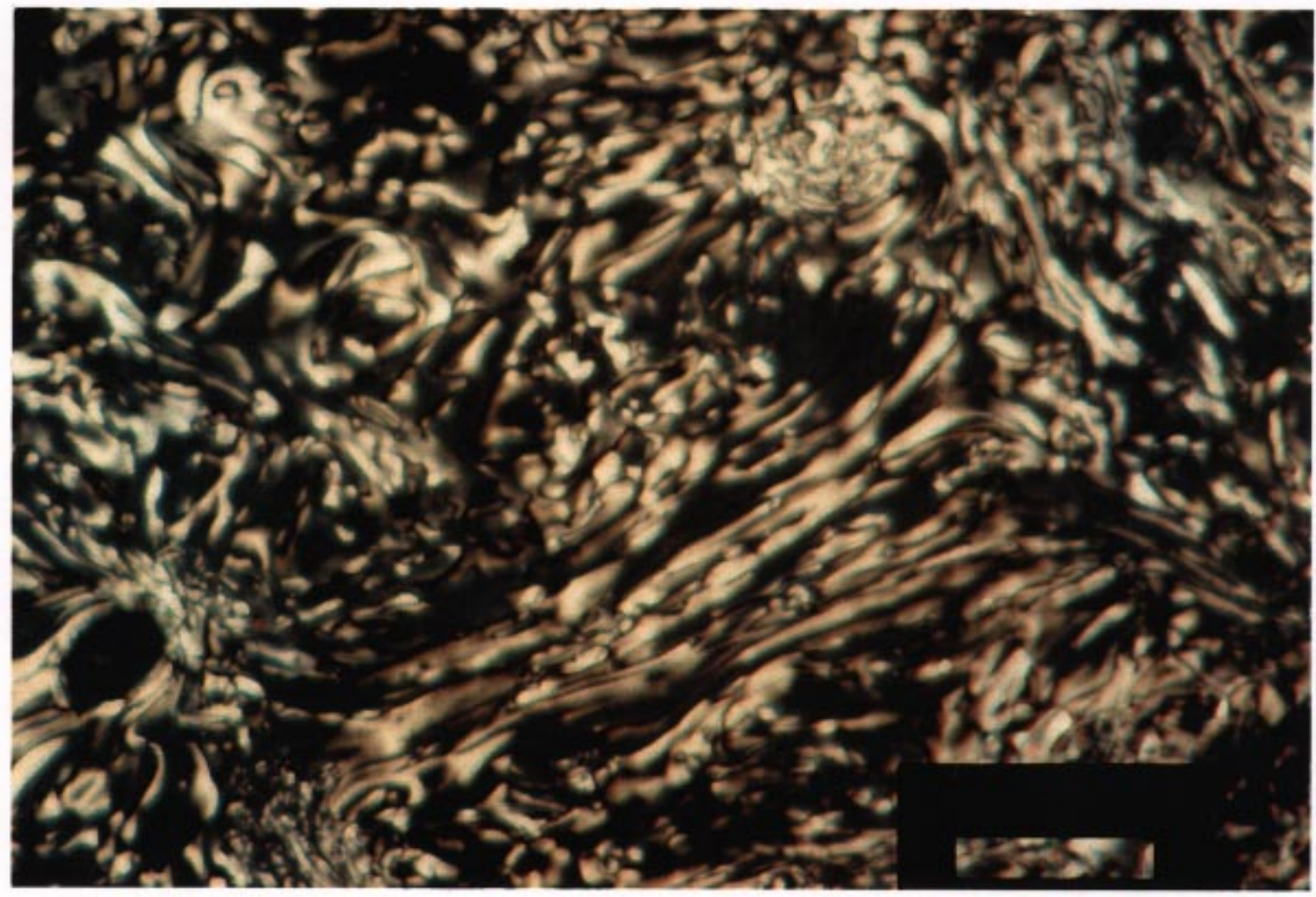

Figure 3. Photomicrograph of NMP-soluble portion of PFS-227-102-14A green coke 
It is evident from the data in Table 6 and the optical texture in Figure 3 that NMP extraction of the PFS produced a low-ash-pitch-like material. The coke yield and softening point temperature are rather low for use as binder pitch, but these values could possibly be improved with additional processing. The development of anisotropy in the green coke is also extensive, suggesting that the NMP extract from the PFS could possibly after further testing find use in the manufacturing of carbon products.

HTI has also sent about $40 \mathrm{~kg}$ of pressure filter solids for testing, as requested by WVU. Preparations are underway to process a sizable quantity of the PFS for examination as a possible precursor for carbon products. 